\title{
情報システム利用者における Small-World 構造の検証 Analysis of social network in campus computer system
}

\author{
堀 幸雄 \\ Yukio HORI
}

\author{
米倉 正和 \\ Yonekura MASAKAZU $\ddagger$
}

\begin{abstract}
本稿は UNIX ワークステーションのアカウンティング情報を用いて利用者のネットワーク構造を抽出する手 法について述べ，得られた大学生計算機利用者の人間関係の特性について考察する。情報システムというように 「人」が主役の場では人の関係が重要である。例えば，初対面の人と会った場合には，自分とその人とのつなが りや，趣味，共通の知人などが分かれば，コミュニケーションがよりスムーズに進むと考えられる。このように 情報システム利用者の社会ネットワークは非常に重要な情報のひとつであると考えられるが，これまで情報支援 の研究において着目されることは少なかった。これは利用者のネットワーク構造を情報システムが獲得すること が困難であるめであると考えらえる。本稿の手法を用いた結果，大学生の人間関係は任意の二者間の平均経路長 が 2.95 人であるスモールワールドネットワークの特徽を持つことがわかった.

In this paper, we propose to extract the socail network of participants from the information system using their accounting records. We discuss the social network feature. In an environment of information system, it is desirable to provide a user with information depending on a user's situation, such as time, location, user behavior, and social context. Since such information was difficult to gain from system, it was rate to be used. We also dicuss the analysis of social network in the campus computer system.
\end{abstract}

\section{1.はじめに}

我々は神奈川大学理学部情報科学科の教育用共同計算 機システムのアカウンティング情報を用いて，端末利用 者間のネットワーク構造を分析した。同時刻に隣席した 利用者同士を関係のある利用者と仮定し，利用者の人間 関係を得た。その結果システムを利用する任意の利用者 二名間の平均経路長が平均 2.99 人であることがわかっ た。同様に任意の米国人 $\mathrm{A}, \mathrm{B}$ と 2 名選び， $\mathrm{A}$ から $\mathrm{B} に$ 人つてに手紙を配送する場合，平均 5.5 人の手を経由す ることで手紙が B に到着することが知られている [15].

情報システムというように「人」が主役の場では人の 関係が重要である。例えば，初対面の人と会った場合に は，自分とその人とのつながりや，趣味，共通の知人な どが分かれば，コミュニケーションがよりスムーズに進 むと考えられる。また大学生という組織全体の人間関係 を見れば，どういう主要な派閥があり，自分はどこにい て，どういう派閥の人とはあまり知り合いがいないか理 解できれば役に立つだろう。人間関係は遠いが，近い内 容の研究をしている人との出会い支援は効果的かも知れ ない.

このように計算機利用者の社会的な人間関係は非常に 重要な情報のひとつであると考えられるが，これまで情 報支援の研究において着目されることは少なかった。そ れは利用者の人間関係の情報をシステムが獲得すること が困難であるためであると考えらえる。

本研究は UNIX ワークステーションの持つアカウン ティング情報を用いて自動的に利用者の組織構造を抽出 する手法を述べ，得られた情報システム利用者である大 学生テムの人間関係がスモールワールド構造を持つか検 証する。

\footnotetext{
†神奈川大学理学部情報科学科

Department of Information Science, Faculty of Science, Kanagawa University

horiyuki@goto.info.kanagawa-u.ac.jp

神奈川大学院理学研究科情報科学専攻

Graduate School of Science, Kanagawa University

kazu@kk.info.kanagawa-u.ac.jp
}

\section{1 関連研究と類似システム}

(1) Web マイニングとしての人間関係ネットワークの 抽出と情報支援 $[14]$

松尾らは Web からユーザ間の人間関係ネットワークを 自動的に抽出する手法を提案している。これは既存の検 索エンジンを用いて，人間関係のつながりのの強さとそ の種類を判断するものである。この手法は検索エンジン を用いるため，大学の情報システムの利用者といったよ うにWebに情報のない人の情報を扱うことができない. 本稿は抽出に用いるデータは情報システムのアカウン ティング情報を用いるため, 検索エンジンに揭載されて いなくても人間関係の抽出が可能である.

(2) FOAF(Friend of a Friend $)^{1}$ の作成と公開 $\mathrm{FOAF}$ は RDF $/ \mathrm{XML}^{2}$ を用いて人間に関する情報とそ の関係を公開，共有する仕組みである。しかし人間関係 全てを手で記述するのは現実的とは言えない。本稿の手 法とはユーザが情報システムを利用するとユーザに関す る情報が自動的に生成される点で異なる。

(3)Social Network を利用したサービス eurekster ${ }^{3}$ は Web 検索にSocial Network を取り入れて サービスを開始している。ユーザの関係する検索傾向を もとに, 同じ組織の他のユーザの求めるものを推測する. また Google が開始した orkut ${ }^{4}$ は今後ビジネス, 趣味, 社交的な関係を構築するために利用されるとしている. 本稿のシステムはユーザに情報支援を行なう是非につい て検討中であるため，これらサービスとの比較は議論し ない.

\section{2. ユーザの要素化と構造分析}

\section{1 ユーザの要素化}

まず学内の教育用共同計算機システム (図 1)の利用者 を対象に個々のユーザのシステム内での行動を要素する 方法について説明する。

\footnotetext{
${ }^{1}$ http://xmlns.com/foaf $/ 0.1 /$

${ }^{2}$ http://ja.wikipedia.org/wiki/ $\{\mathrm{RDF}, \mathrm{XML}\}$

${ }^{3}$ http://www.eurekster.com

${ }^{4}$ http://www.orkut.com/
} 


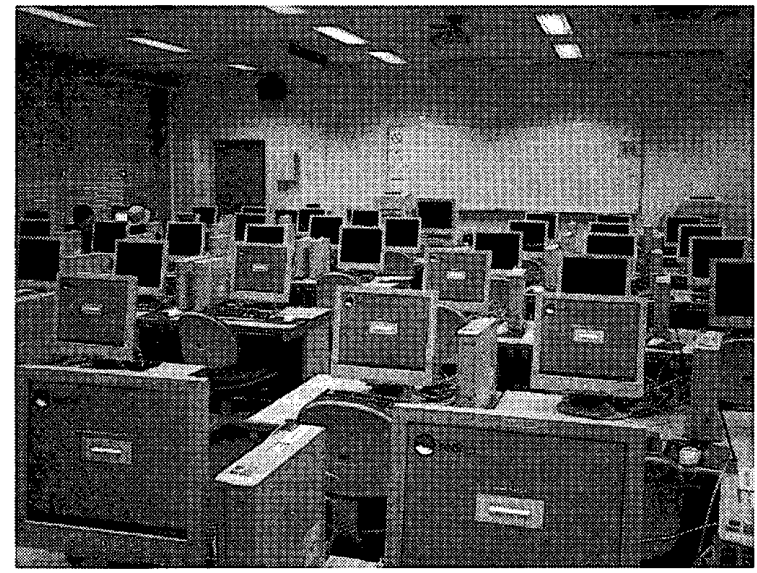

図 1: 学内教育用共同計算機室

ユーザのシステム内での行動を要素化するには，シス テムからアカウンティング情報を取得し, 各利用者 $\left(x_{i}\right)$ ごとに使用したプロセス $\left(p_{i}\right)$ を使用頻度で重み付けした $n$ 次元のベクトル $u_{i}$ を用いる $($ 式 $(1))$. アカウンティ ング情報は一般的にUNIX で用いられている acct ${ }^{5}$ を 使用する。このアカウンティング情報はユーザベースの プロセスの情報を記録・管理している。

$$
\begin{array}{r}
u_{i}=\left\{P\left(x_{i}: p_{1}\right), P\left(x_{i}: p_{2}\right), \cdots, P\left(x_{i}: p_{n}\right)\right\} \\
\text { ただし } P\left(x_{i}: p_{k}\right)=\sum_{j=1}^{m} w^{j-1}
\end{array}
$$

\section{2 ネットワーク構造の抽出}

学内の情報システムは課題, 演習などを行なうことを 目的とし，さらに学外ネットワークから利用できない環 境にあるため物理的に計算機室にて使用することになる。 計算機室を利用する人が多いほど，計算機室が賑やかに なるのはコミュニケーションを行なう友人が近くに居る と考えられる (図 2). したがって隣席関係をなんらかの 関係のある利用者同士と仮定して，ネットワーク構造を 抽出する。たたし偶然に関係のない利用者間が隣席する ことも考えられるので，閾値として月に 1 時間以上隣席 を設定した。

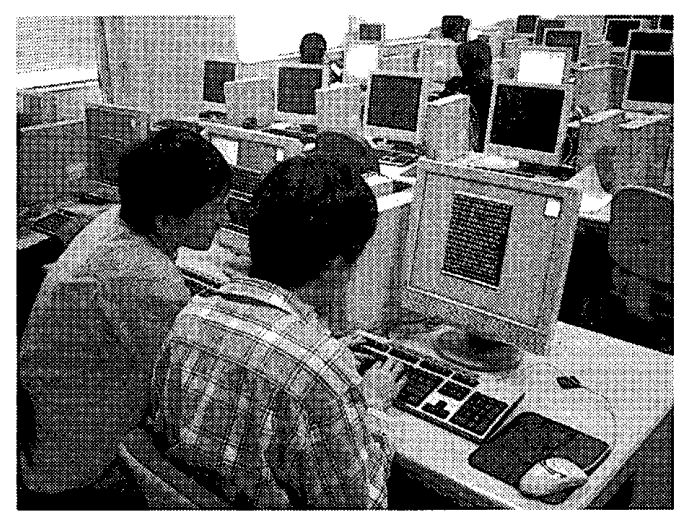

図 2: うるさい隣席

\section{3 実 現}

隣席関係の抽出はシステムのアカウンティング情報か らログイン記録 6 と座席表から機械的に抽出した。分析 対象のデー夕を表 1 に示す。括弧内の数值は月に 1 時 間以上という䦨値を越えた値である。

\begin{tabular}{rr} 
表 $1:$ 対象データ \\
\hline \hline 実験期間: & 2003 年 9 月 20 日 \\
& 2003 年 12 月 31 日 \\
総利用者数: & $2,369(777)$ \\
総隣席数: & $5,108(1,548)$ \\
\hline
\end{tabular}

\section{4 関 係の検 証}

こうして得られたユーザ (大学生)の人間関係が実際 の人間関係の強さと同じであるのかについて検証する。 実際の人間関係の場合には関係には, 今回得た同じ時間 を過ごすといった強さだけでなく、「友人」や「サークル のメンバー」といった種類がある。このような関係の種 類には，

1. 研究室: 同じ研究窒のメンバーである。

2. 発表: 同じ研究会や大会で発表している。

4. 作業内容: 同じレポート, 演習等に取り組んでいる. 等が考えられる。

隣席時間とこの利用者の使用内容との分布を図 3 に示 す。横軸は隣席時間であり，縦軸は二者間のプロセスの 使用べクトルのなす余弦 $(\cos \theta)$ の值である。

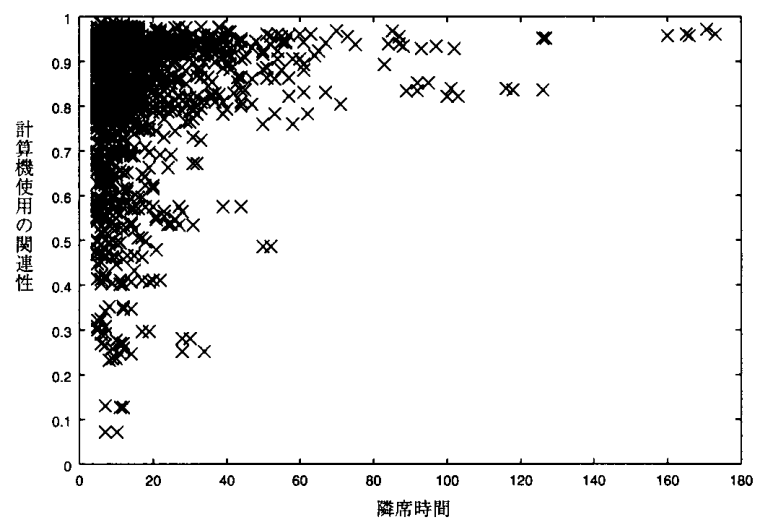

困 3: 二者間の隣席と計算機使用の分布

図 3 より二者間の隣席時間が増えると，計算機の使用 内容が似ていくのがわかる、どのようなプロセスに使用 傾向があるのかは個々の利用者の使用プロセスのベクト ルの成分や大きさを見ることでわかる。

また得られたネットワークについて 2，3 名にネット ワーク質問を行ない，自分のまわりの人間の氏名を言っ てもらつたところ全員本人と $1 ， 2$ 段階の関倸を持つ利 用者であることがわかった。

このように隣席時間と計算機の使用内容と強い関係が あり，実際の知り合いとも等しいことから，本研究で得 られたネットワークが実際の人間関係ネットワークと大 きく違いはないと思わ执る。

\section{3. 関係の可視化}

図 4 に情報科 3 年生の利用者間の人間関係ネットワー クを示す。全体の図示は困難であるので，中心的な (人 数の大きい派閥) ネットワークを示している.

\footnotetext{
${ }^{6}$ utmp,wtmp,lastlog 等
} 
表 2: 各種ネットワークの指標

\begin{tabular}{cccc}
\hline \hline ネットワーク & 平均距離 & クラス夕係数 & ノード数 (リンク数 $)$ \\
\hline 大学生の計算機利用者 & 2.95 & 0.63 & $777(1,548)$ \\
\hline 物理学者の共著 & 4.0 & 0.726 & $56627\left(4.898 \times 10^{6}\right)$ \\
医学研究者の共著 & 4.6 & 0.07 & $1.389 \times 10^{6}\left(1.028 \times 10^{7}\right)$ \\
二ューロン & 2.65 & 0.28 & - \\
電力線 & 18.7 & 0.08 & $4941(6,610)$ \\
Web & 3.7 & 0.24 & $325729\left(1.470 \times 10^{6}\right)$ \\
\hline
\end{tabular}

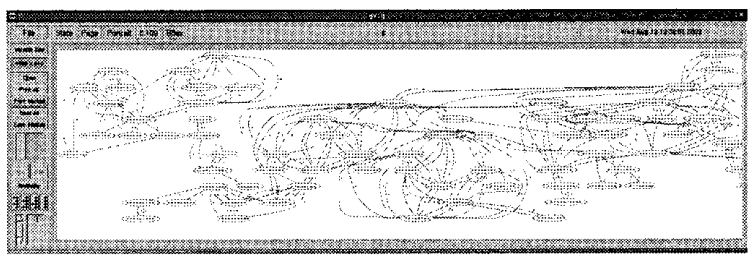

図 4: 人間関係ネットワーク全体

また図 5 に一部を拡大したものを示す。それぞれの点 は利用者に対応しており，辺には「隣席時間」のラベル がつけられている。

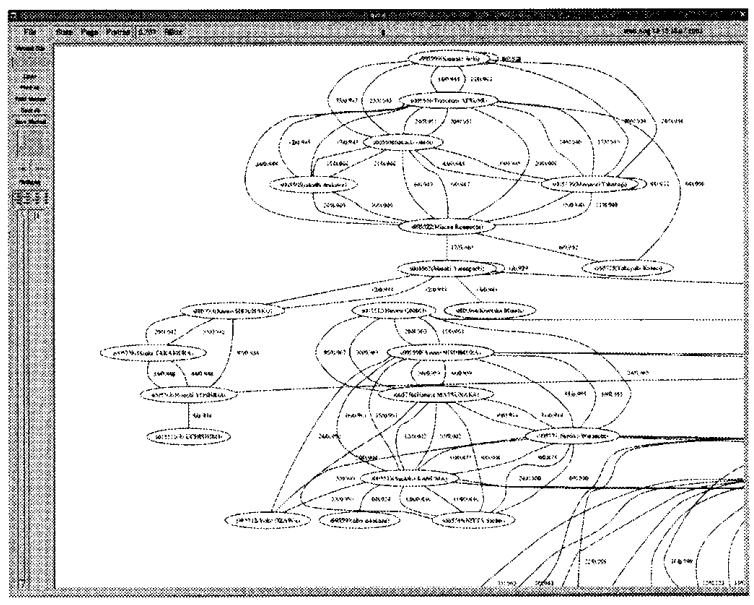

図 5: 人間関係ネットワークの一部

\section{4. ユーザのネットワーク構造の分析}

ここで得られた計算機システムを利用する大学生の人 間関係ネットワークを分析する。組織構造の特徵量には 様々なものがあるが，分析の全般的な詳しい説明は文献 [24] に譲り，ここでは Watts がスモールワールドネット ワークを定式化するために用いた 2 つの特徵量 [22] を 扱う。

\section{1 スモールワールドネットワークの定式化}

Duncan Watts はグラフにおいて次の 2 つの特徴量に よりスモールワールドネットワークを定式化した。

a) L(characteristic path length): グラフ中のすべての 点の組についての最短経路の長さの平均.

b) $\mathrm{C}$ (clustering coefficient): 共通の知人を持つ二者問 が直接の知人である確率についての平均。これはグ ラフ中の点 $i$ が $k$ 本の辺を持っている場合， $k$ 個 の点の間に存在する辺の数を $m$ としたとき，(2) 式 で表わされる。

$$
\begin{aligned}
C_{i} & =\frac{m}{k(k-1) / 2} \\
C & =\frac{1}{n} \sum_{1}^{n} C_{i}
\end{aligned}
$$

なおスモールワールドネットワークとは, 点がクラスタ 状に集まっているにも関わらず，点同士の経路が短かい という特幑を持つグラフである。図 6 は $\beta$-Graph と呼 ばれるスモールワールドのモデルである。まず $n$ 個の ノードがそれぞれ近傍の $k$ 個のノードに辺が張られて いるレギュラーグラフを考える.そして各辺に対して確 率 $p$ で辺のつなぎかてできるグラフにおける L と C の值を $p=0$ の值 $L(0), C(0)$ で規格化して表示してあ る. $p$ が中間的な值を持つときに，小さな L かつ大き な C を持つことがわかる。この C の曲線と L の曲線に 挟まれた領域をスモールワールドネットワークと呼ぶ。

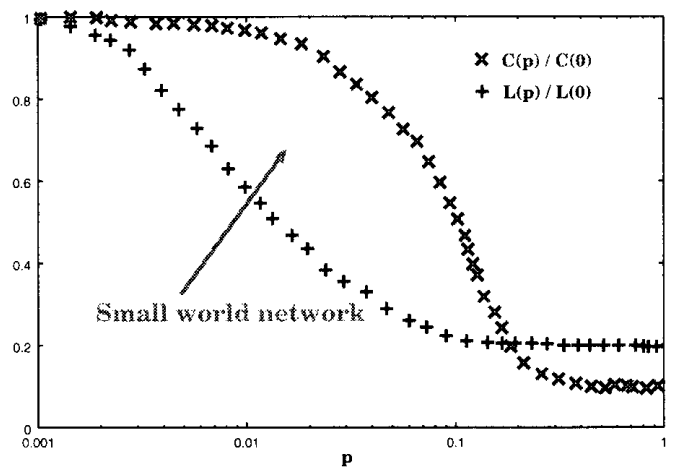

図 6: スモールワールドのネットワーク構造

本稿で得られた学内の情報システムの利用者の組織構 造量を分析した結果,

- C: 0.63

- L: 2.95

という值であった。同様にこの指標についてこれまで分か つているネットワークを表 2 に示す [1][3][17] [19][21][22] 表 2 から本研究で得た大学生の計算機利用者の組織構 造も他の組織同様に平均経路が短かく，高クラス夕係数 のネットワークであることがわかる。

\section{2 スモールワールドの特性}

また Watts はスモールワールドネットワークでは流 行や伝染病が伝わりやすいことを示している $[23]$. 彼が 用いたモデルでは, 時間 $t=0$ で 1 名の人が病気にな る。病気になった人は近傍の人に確率 $p$ で病気を伝染 し, ネットワークから除加れる。最終的に, 病気の流行 
が終わるか，病気が広がって人がいなくなるまでこれを 繰り返す。

このモデルを用いたシミュレーションの結果 $\mathrm{L}$ が小 さいスモールワールドネットワークでは，伝染は短時間 に広まるということがわかっている。

他にもスモールワールドの性質として，ダメージに対 して強いことがあげられる。ランダムに点を除去しても， グラフにおける点の距離はそれほど変わらず，影響は少 ない.しかし点が集中している点(ハブノード)を選択 的に攻撃した場合には，ダメージが大きいのである [1]. つまりランダムの攻撃に対するロバスト性と，狙いを つけた攻撃に対する脆弱性の両面がスモールワールドの 特徴である。

\section{5. 討 論}

本研究は，利用者の組織構造に対する情報支援という 観点から計算機利用者の組織構造を抽出し, 分析を行 なった。その結果，計算機システムを利用する大学生間 の人間関係ネットワークの平均経路長が 3 であること がわかり，かつスモールワールドの特性を持つことがわ かった。

もちろん，隣席関係だけからは推測できない関係も存 在する。例えば，隣席関係上には情報がないほど新しい 関係や，形式的に現われないような関係 (昔の友人関係) を隣席情報から得るのはむつかしい。しかし，計算機シ ステム上の隣席情報には人間関係を近似的に取り出すに は十分な情報がある。また今後ますます多くの情報が電 子的に利用可能になると思われる。

ただし，いくつか考慮しなければならない点がある。 アカウンティング情報の利用に関する問題 7 , 利用者の プライバシに関する問題など，社会的な合意がまだ不十 分でむつかしい問題であるが, サービス提供の際には十 分な配慮を行なうことが必要である。

\section{6. おわりに}

本研究では，人間関係ネットワークを計算機システム から抽出する手法を提案したが，どういう人間関係の人 が近くにいるときにどういう支援を行なえば良いのか， 人間関係ネットワークの位㯰と利用者の活動状況の関係 はあるのか，活発な派閥の人間関係ネットワークはどう いう特徴を持っているのかなど, 今後，さまざまな研究 が可能であると考えられる。本研究はューザの名前とそ の行動から，その間の関係を網羅的に取り出すことが可 能である。

したがって，流行や情報，知識の流れという点におい て, 組織がどう存在するのかを特徴づける方法や, 本研 究で得た利用者を取り巻く人間関係から, 利用者の活動 情報, 欲求, 嗜好, これまでの履歴を考慮し，利用者の 文脈に応じた情報支援の方法などが残された問題である。

\section{謝辞}

実験データを提供して頂いたシステムの利用者の皆様 に感謝致します。

\section{参考文献}

[1] Albert, R., Jeong, H., Barabási, A.-L.: Diameter of the World-Wide Web, Nature, Vol.401, pp.130-131, 1999.

[2] Amaral, L. A. N., Scala, A., Barthélémy, M., Stanley, H. E.: Classes of small-world networks, Proc. Natl. Acad. Sci. USA, Vol. 97, pp. 11149-11152, 2000.

[3] Barabási, A.-L., Albert, R.: Emergence of Scaling in Random Networks, Science, Vol.286, pp.509-512, 1999.

7アカウンティング情報はもともと課金目的のために設計されたも のである
[4] Barabási, A.-L.: Linked: The New Science of Networks, PerseusPublishing, 2002. (青木訳: 新ネットワー ク思考, NHK 出版, 2002).

[5] Brin, S. , Page, S.: The Anatomy of a Large-Scale Hyptertextual Web Search Engine, Proc. of the 7th International World Wide Web Conference, 1998.

[6] Buchanan, M.: Nexus: Small Worlds and the Groundbreaking Science of Networks, W.W.Norton \& Company, 2002.

[7] Davidsen, J., Ebel, H., Bornholdts, S.: Emergence of a Small World from Local Interactions: Modeling Acquaintance Networks, Physical Review Letters, Vol. 88, No. $12,2002$.

[8] Dorogvtsev, S. N., Mendes, J. F. F.: Evolution of Network, Oxford University Press, 2002.

[9] 福田 健介他: ac.jp ドメインにおけるドメイン内 Web リンク構造の解析. 情報科学技術フォーラム, 情報処理学 会, 2003 .

[10] Girvan, M. , Newman, M. E. J.: Community Structure in social and biological networks, Proc. Natl. Acad. Sci. USA, Vol.99, pp.7821-7826, 2002.

[11] Kleinberg, J.: Authoritative sources in a hyperlinked envitonment, Proc. 9th ACM-SIAM Symposium on Dicrete Algorithms, 1998.

[12] Marchiori, M., Latora,V.: Harmony in the small-world, physica A, Vol.285, pp. 539-546, 2000.

[13] Mathias, N., Gopal, V.: Small worlds: How and why, Physical Review E, Vol. 63, No. 2, 2001.

[14] 松尾 豊, 友部 博教, 橋田 浩一, 石塚 満: Web 加の人 間関係ネットワークの抽出と情報支援, 人工知能学会全 国大会、1F1-02, 2003.

[15] Milgram, S.: The small world problem, Psychol. Today, Vol. 2., pp. 60, 1967.

[16] Mossa, S., Barthelemy, M., Stanley, H. E., Amaral, L. A. N.: Truncation of power law behavior in "scale-free" network models due to information filtering, Phys. Rev. Lett., Vol. 88, p.138701, 2002.

[17] Newman, M.E.J.: The structure of scientific colaboration networks, Proc. Natl. Acad. Sci. USA, Vol.98, pp.404-409, 2001.

[18] Newman, M.E.J.: Who is the best connected scientist ? A study of scientific coauthorship networks, Phys. Rev. E, Vol. 64, p.016132, 2001.

[19] Pastor-Satorras, R., Vazquez, A., Vespignani, A.: Dynamical and correlation properties of the Internet, Phys. Rev. Lett., Vol.87, p. 258701, 2001.

[20] Press, W. H., Teukolsky, S. A., Vetterling, W. T., Flannery, B. P.: Numerical Recipes In C, Cambridge University Press, London, 1998.

[21] Strogatz, S.H.: Exploring complex networks, Nature, Vol. 410, pp.268-276, 2001.

[22] Watts, D. J., Strogatz, S. H.: Collective dynamics of 'small-world' networks, Nature, Vol.398, pp.440-442, 1998.

[23] Watts, D. J.: Small World, Princeton Univ, Press, 1999.

[24] 安田 雪: ネットワーク分析, 新曜社, 1997.

[25] 安田雪: 実践ネットワーク分析, 新曜社, 2001.

[26] 石川大介, 堀 幸雄: 端末利用者間におけるグラフの分析, 情報処理学会，第 64 回全国大会，2002.

[27] 堀 幸雄, 石川大介: 端末利用者間のネットワーク分析, 情 報化学技術フォーラム 2003, 情報処理学会.

[28] 田代 淳一, 堀 幸雄 後藤 英一：アカウンティング情報を 用いた利用者の尃門性分析, 情報処理学会, 情報システ 么研究報告 No.83, Vol.2003. 